\title{
Entre meios e formatos: diferentes maneiras de conhecer histórias e personagens da América Latina
}

\author{
Maria Ignês Carlos Magno \\ Doutora em Ciências da Comunicação pela ECA/USP. \\ Professora do Mestrado em Comunicação da Universidade Anhembi Morumbi e da Fundação \\ Escola de Sociologia e Política de São Paulo. \\ E-mail: unsigster@gmail.com
}

Resumo: A Videografia deste número demonstra que, na atual sociedade em rede, as informações estão para além das páginas dos livros e das salas de aula, disseminadas nos mais diferentes suportes de comunicação. Desse modo, o professor não precisa apenas se ater às sequências dos conteúdos do livro didático, mas partir de uma das informações e/ou recursos audiovisuais para tratar dos conteúdos programáticos. A Revolução Cubana registrada pelas lentes de Alberto Korda e a trajetória política de Ernesto Che Guevara, contada em três filmes - Diários de motocicleta, de Walter Sales, Che: Part One e Che: Part Two (A guerrilha), ambos de Steven Soderbergh, são exemplos utilizados na seção para a aplicação destes recursos.

Palavras-chave: escola, educação, fotografia, revolução cubana, cinema.
Abstract: This issue's videography demonstrates that in today's networked society, information is beyond the pages of books and classrooms, being disseminated in several formats. Thus the teacher does not need to restrict himself to the sequences of the textbook contents, he can depart from an information and/or audiovisual resources to address the programmatic contents. The Cuban Revolution recorded by the cameras of Alberto Korda and the political trajectory of Ernesto Che Guevara, told in three films - The Motorcycle Diary, by Walter Sales, Che Part One: the Argentine and Che Part Two: Guerrilla, by Steven Soderbergh - are examples used in this section for the application of those resources.

Keywords: school, education, photography, Cuban Revolution, cinema.

Todos se dejan la barba y el pelo como él Pero no son como él

Todos se declaran y hablan em nombre de él

Como si fuera él

Yo me pregunto que estará pensando él 
comunicação \& educação • Ano XV • número 2 • maio/ago 2010

\author{
Si pudiera ver \\ Como se llenan de plata hablando de él \\ Sin saber nada de él \\ Todos se compran la remerita del Che, \\ si saber quién fue \\ Su nombre y su cara no paran de vender \\ Parece McGuevara's, o CheDonald's \\ No es hermano de Fidel ni pariente de Pino'che. \\ El nació en Argentina y salió a recorrer \\ No es de la época de Evita y a pesar del musical \\ Nunca fue asistente de Peron, el General \\ Yo me pregunto por qué le toco a él \\ Ser Jesucristo al final del milenio, Che, eh, Che... \\ Y lo mataron como un perro en Bolivia \\ Vuelve y vuelve mil veces al que matan así \\ $\mathrm{O}$ es que al final nunca muere \\ El que no teme morir \\ Parece Mcguevara's, o CheDonald's'.
}

Em andança pela internet, uma notícia em um site português me chamou a atenção, apesar de já passada. Era sobre a exposição das fotografias de Alberto Korda Gutierrez sobre a Revolução Cubana². A matéria trazia como manchete o fato de que naquele período o grande público podia conhecer as fotografias Korda. Seria uma notícia entre tantas outras que encontramos, lemos e vemos na rede todos os dias se Alberto Korda não tivesse sido o fotógrafo quem, com apenas dois disparos de sua Laica, eternizou um dos rostos mais conhecidos e reproduzidos da história da humanidade: Ernesto Che Guevara, cujo título dado pelo fotógrafo foi Guerillero Heroico. Lembrei-me de que em 1o de janeiro de 2009 a Revolução Cubana completou 50 anos, sem grandes festas ou recordações por aqui, seja na mídia, seja nas salas de aula. Lembrei-me também de que, entre 2008 e 2009, dois filmes de Steven Soderbergh trouxeram novamente aspectos da vida e da trajetória política de Che Guevara: Che: Part One e A guerrilha, formando, juntamente com Diários de motocicleta (2005) de Walter Salles, uma trilogia sobre Ernesto Che Guevara e sua luta revolucionária na América Latina: Guatemala, México, Cuba, Bolívia. Alguns cliques a mais e em vídeos disponibilizados no Youtube, o músico argentino Kevin Johansen resumia em sua canção McGuevara's o CheDonald's as inúmeras apropriações feitas da mesma imagem: imagem do homem; imagem-mito; imagem-produto de consumo; imagem-mercadoria em que tudo se transforma nesse sistema econômico; imagem-símbolo de resistência e persistência históricas - resistência em tempos revolucionários, persistência em tempos de efemeridades. Informações distintas, fragmentos de realidades disponíveis em diferentes formatos e meios de comunicação que, se bem agrupados, podem servir de fios condutores para um estudo sobre a América Latina.

Ter iniciado esta introdução com a notícia retirada de um site português, sobre a exposição fotográfica de um cubano realizada em Portugal, foi proposital, 
uma vez que são dois os objetivos a serem demonstrados: o primeiro, é o de que na atual sociedade em rede as informações estão para além das páginas dos livros e das salas de aula, disseminadas nos mais diferentes suportes de comunicação; e o segundo, é de que o professor não precisa apenas se ater às sequências dos conteúdos do livro didático, mas partir de uma dessas informações e/ou recursos audiovisuais para tratar dos conteúdos programáticos. No caso, a Revolução Cubana registrada pela lente de Korda e inscrita nas películas cinematográficas.

\section{DA FOTOGRAFIA À HISTÓRIA. ERNESTO CHE GUEVARA E ALBERTO KORDA GUTIERREZ}

Interessante quando histórias se encontram como que ao acaso. E essa é a primeira história que pode ser conhecida para iniciar o desvendamento das histórias da América Latina, das quais as representações fotográficas ou cinematográficas são pontos de partidas: a história dos nomes. Alberto Korda, o homem que fotografou Che Guevara, chamava-se Alberto Díaz Gutierrez. $\mathrm{O}$ nome Korda ele criou para homenagear os cineastas húngaros Zoltan e Alexander Korda, e mais a marca Kodak. Foi vendedor de produtos farmacêuticos até criar seu próprio estúdio de fotografias publicitárias e de moda. Che Guevara chamava-se Ernesto Guevara de La Serna. O apelido Che surgiu no México, quando conheceu Fidel Castro e o grupo de guerrilheiros que preparavam a invasão a Cuba. $\mathrm{O}$ jeito argentino de falar o tempo todo a interjeição Che lhe valeu o título de Dr. Che Guevara. De fotógrafo de modelos, Korda se transformou no fotógrafo da Revolução. De 1959 a 1968, ficou ao lado de Fidel Castro. De médico dos guerrilheiros a um dos líderes da revolução, Che ficou ao lado de Castro até 1965, quando deixou o cargo de ministro da Economia e foi para a Bolívia.

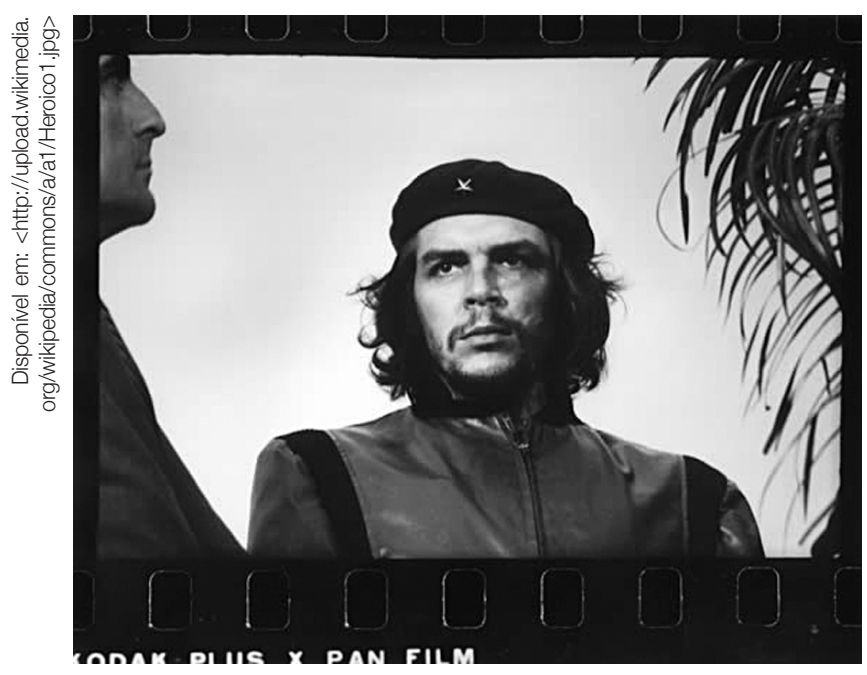

A foto tirada ao acaso no dia 5 de março de 1960 tem sua própria história e é parte de uma história maior. Nesse dia, quando Fidel Castro discursava em homenagem às vítimas da sabotagem e da explosão do cargueiro francês La Coube que levava armas para Cuba, Che surgiu. Korda, então fotógrafo do jornal Revolución e que estava no local fazendo a cobertura do evento, bateu duas fotos. Che

Guevara se virou e deixou o local. Nada mais que dois disparos de uma Laica e a fotografia de Ernesto Che Guevara se transformou em um ícone até os 
comunicação \& educação • Ano XV • número 2 • maio/ago 2010

dias atuais. A foto recortada de um evento e tratada em laboratório fotográfico, aparentemente estática, é um fragmento da história da Revolução Cubana, da América Latina e da trajetória política de Ernesto Che Guevara. Embora essa seja a foto mais famosa de Alberto Korda, não é a única. Ele registrou todo o processo da revolução. São 52 mil negativos guardados no Arquivo Histórico do Conselho de Estado de Cuba. Korda registrou a revolução. Che fez a revolução e registrou sua trajetória em Diários.

Se a revolução uniu Alberto Korda e Che Guevara, as duas histórias interessam porque se desdobram em outras histórias e em possibilidades de pesquisas. Histórias e registros que também se transformaram em livros e filmes.

\section{DA HISTÓRIA AO CINEMA. E O CONTRÁRIO TAMBÉM}

A trajetória política de Ernesto Che Guevara foi contada em três filmes: Diários de motocicleta, de Walter Salles, Che: Part One e Che: Part Two (A guerrilha), ambos de Steven Soderbergh.

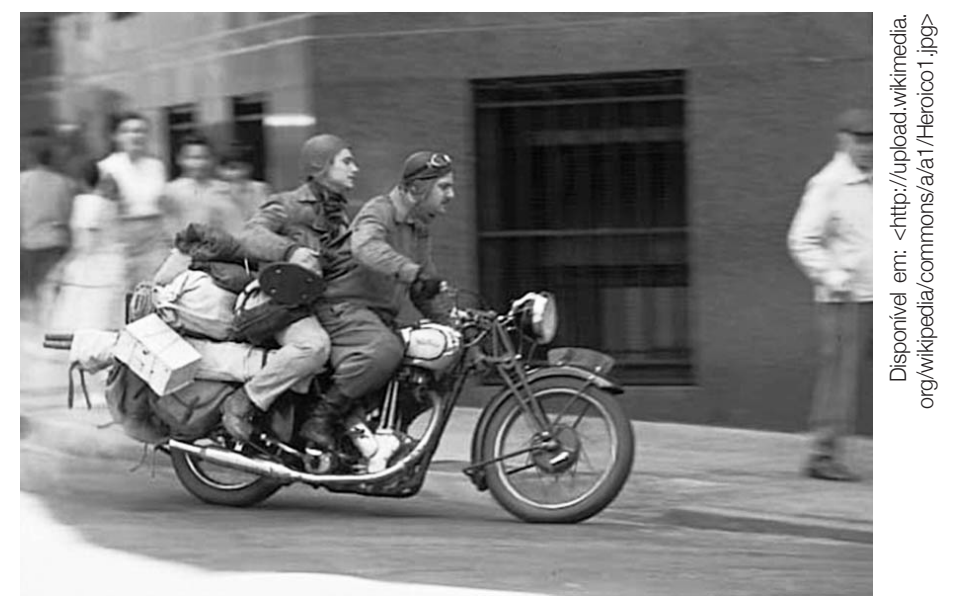

\section{FICHA TÉCNICA}

Diários de motocicleta

Título original: The Motorcycle Diaries

Direção: Walter Salles

Gênero: drama

Roteiro: José Rivera, baseado no livro de Che Guevara e Alberto Granado Fotografia: Eric Gautier

Edição: Daniel Rezende

Duração: 128 minutos

Ano: 2004

Em Diários de motocicleta, Salles conta a história de Ernesto Guevara, um jovem estudante de medicina que, em 1952 e com apenas 22 anos, decide juntamente com seu amigo Alberto Granado viajar pela América do Sul de 
motocicleta. Após oito meses, a motocicleta quebra e o restante da viagem é realizado por meio de caminhadas e caronas. Quando chegam a Machu Picchu, conhecem uma colônia de leprosos e, a partir da travessia do rio e da convivência com os doentes, Ernesto passa a questionar a vida dos pobres ante o abandono dos governos locais. Alberto voltou para a Argentina e Guevara seguiu viagem por outros países da América. Em entrevista dada a Folha de S. Paulo em 11 de julho de 2005, Walter Salles deixa claro que a vida de Che transcende em muito o cinema; que seu desejo com o filme era mostrar uma história de descobrimentos dos jovens latino-americanos naqueles anos e também mergulhar num continente desconhecido. Segundo Salles, naquela viagem os dois amigos mostraram que esse continente não é irrelevante. Para todos que viram o filme ficou a pergunta: e o Che revolucionário?

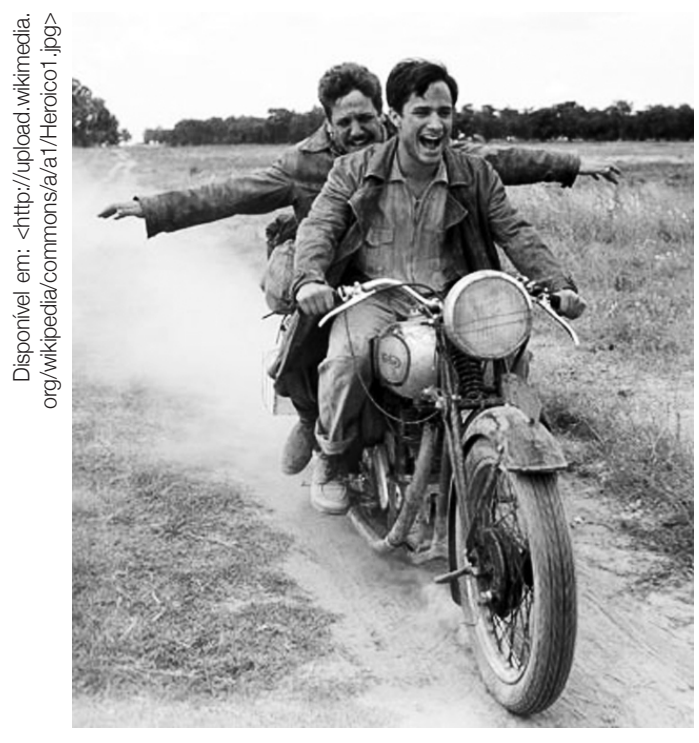

O Ernesto revolucionário viria um pouco mais tarde, tanto na vida real como no cinema. Foi na Guatemala que ele se juntou às milícias populares que lutavam e defendiam o governo popular de Jacob Arbénz, ameaçado por uma invasão organizada pela CIA. Com a derrota do governo de Arbénz, Guevara pediu exílio no México. Lá, Fidel Castro também estava exilado após o assalto cometido ao quartel Moncada. Foi no México que Guevara conheceu e se juntou ao grupo de Fidel que preparava a invasão à Cuba e a revolução. Em 26 de novembro de 1956, Fidel viaja do México para Cuba com oito revolucionários, entre eles Ernesto Che Guevara. De início como médico da guerrilha, passa em seguida a integrar a guerrilha para derrubar o governo do ditador Fulgêncio Batista. Essa história pode ser acompanhada no filme Che: Part One, de Steven Soderbergh.

\section{FICHA TÉCNICA}

Título original: Che: Part One

Dirȩão: Steven Soderbergh

Gênero: drama

Roteiro: Peter Buchman, baseado em livro de memórias de Ernesto Che Guevara

Música: Alberto Iglesias

Fotografia: Steven Soderbergh

Edição: Pablo Zumárraga

Duração: 126 minutos

Ano: 2008 
comunicação \& educação • Ano XV • número 2 • maio/ago 2010

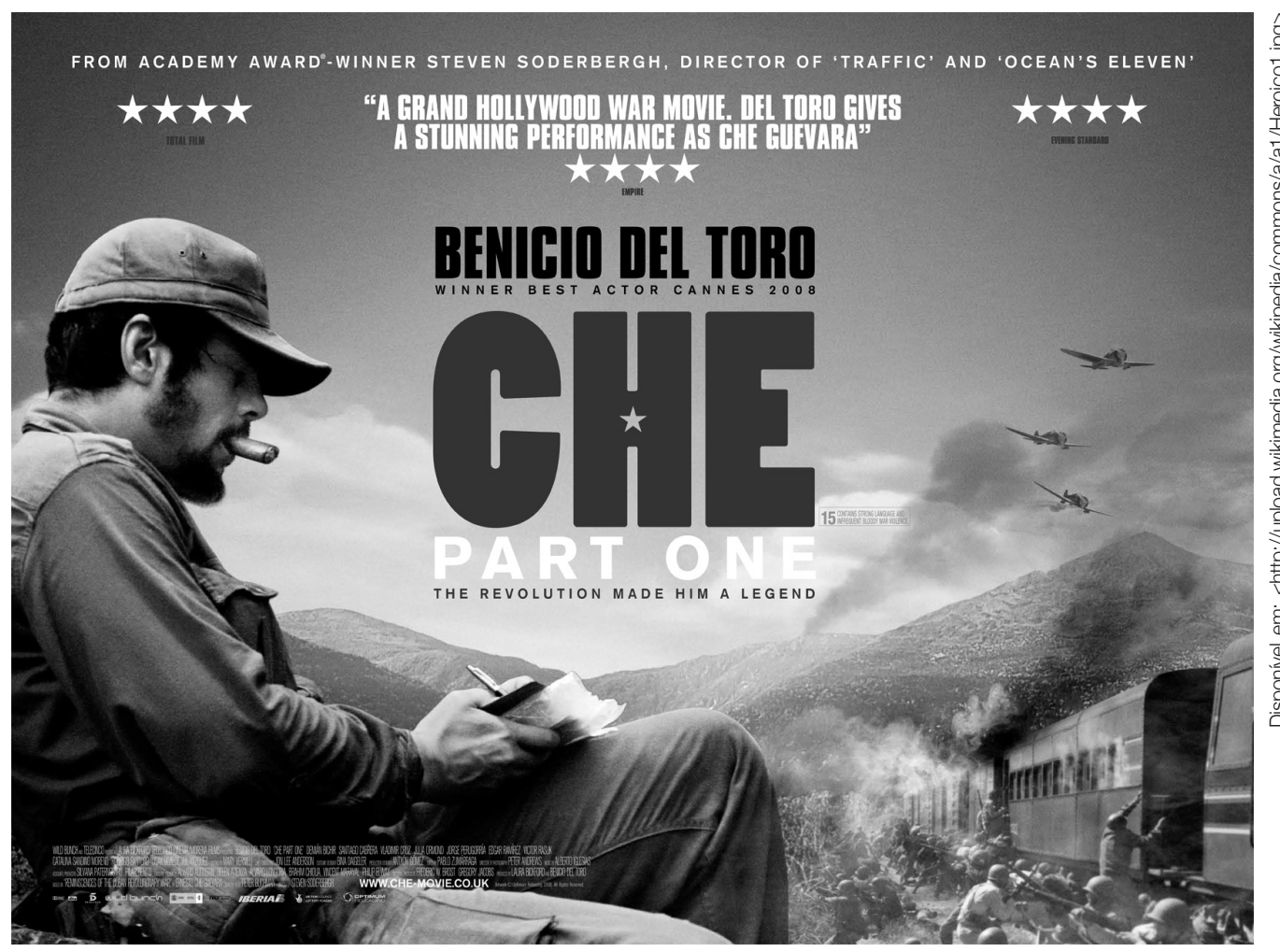

Na sequência, o mesmo diretor completa a história da trajetória política de Che Guevara com o filme Che: Part Two (A guerrilha).

\section{FICHA TÉCNICA}

Che 2: A guerrilha

Titulo original: Che: Part Two

Direção: Steven Soderbergh

Gênero: drama

Roteiro: Peter Buchman e Benjamin A. van der Veen

Música: Alberto Iglesias

Fotografia: Steven Soderbergh

Duração: 135 minutos

Edição: Pablo Zumárraga

Ano: 2008

Che: Part Two (A guerrilha) narra a história de Che após a revolução vitoriosa. Che Guevara era ministro da Economia em Cuba, quando, mesmo no auge do poder, deixa o cargo, desaparece e ressurge incógnito na Bolívia para começar o que chamava de a grande revolução latino-americana. O filme na verdade mostra a campanha boliviana de Che e seu pequeno grupo isolado em território desconhecido e sem o apoio do partido comunista local. Perseguido pelo exército boliviano, foi preso e assassinado no povoado de La Higuera. 
Concordando com as palavras de Salles de que qualquer tentativa de narrar a trajetória completa de Che seria um exercício redutor, proponho tomar a ficção e desvendar os fatos e as histórias reais. Se Diários de motocicleta de Walter Salles nos favorece a descoberta das geografias e das histórias da América do Sul, os filmes de Soderbergh nos levam a duas situações interessantes. Se Che: Part One nos mostra o processo revolucionário em Cuba, que está, mesmo que minimamente, contado em todos os livros de história, Che: Part Two (A guerrilha) nos coloca na mesma situação de Che na Bolívia: em um território desconhecido historicamente. Nada ou quase nada é trazido nos livros sobre a trajetória boliviana e muito menos sobre a guerrilha na Bolívia. E esse é o valor dos filmes e ponto de partida para uma proposta de atividade.

Apesar de os estudos sobre a América Latina ganharem nos livros didáticos alguns períodos históricos e capítulos quase sempre atrelados aos acontecimentos da história europeia, norte-americana ou a episódios contemporâneos, algumas escolas, apoiadas nos Parâmetros Curriculares, incorporaram em seu currículo os estudos relativos à História da América Latina. Fato que nos anima a incentivar a realização de atividades que possibilitem ao professor e ao alunado trabalharem além dos recursos oferecidos pelos livros didáticos. Conforme o título da exposição de Korda: Conhecido desconhecido, a América Latina, suas histórias e personagens merecem sair das sombras de outras histórias, ser investigadas, expostas e dadas a conhecer. A ideia é trabalhar a ausência daquilo que nem o filme nem os livros trazem: a história da Bolívia e das lutas revolucionárias na década de 1960, e a luta particular de Che que culminou com sua morte em 8 de outubro de 1967; o desaparecimento de seu cadáver por três décadas; o encontro de seus restos mortais pelos arqueólogos em 17 de outubro 1997 sob o asfalto do aeroporto de Vallegrande, perto de onde foi executado; e o nascimento do mito não só pela mídia ou pela foto famosa, mas também pelos moradores de Vallegrande, que elevaram Che Guevara à condição de beato, onde ficou conhecido como San Ernesto de La Higuera ${ }^{3}$.

\section{REFERÊNCIA BIBLIOGRÁFICA}

LOVINY, Christophe; SILVESTRI-LEVY, Alessandra; KORDA, Alberto. Cuba por Korda. São Paulo: Cosac \& Naify Editora, 2004.

\section{Endereço eletrônico}

JOHANSEN, Kevin. McGuevara's o CheDonald's. The Nada, ( ) Los Años Luz Discos, 2000. 1 CD. Disponível em: <http://www.kevinjohansen.com/2007/en/ mcguevara-s-o-chedonald-s.html .
3. LOVINY, Christophe; SILVESTRI-LEVY, Ales sandra; KORDA, Alberto. Cuba por Korda. São Paulo: Cosac \& Naify Editora, 2004. 


\section{gostosa de

Se você pode enxergar, experimente fechar os olhos e sentir o braile, por meio das muitas histórias preparadas para as crianças nos livros escritos em tinta e braile. Quando você se der conta dessa magia e abrir os olhos, em seu olhar vai caber um mundão de gente. E se você não pode enxergar, tem agora novos motivos para desbravar o mundo mágico da leitura.

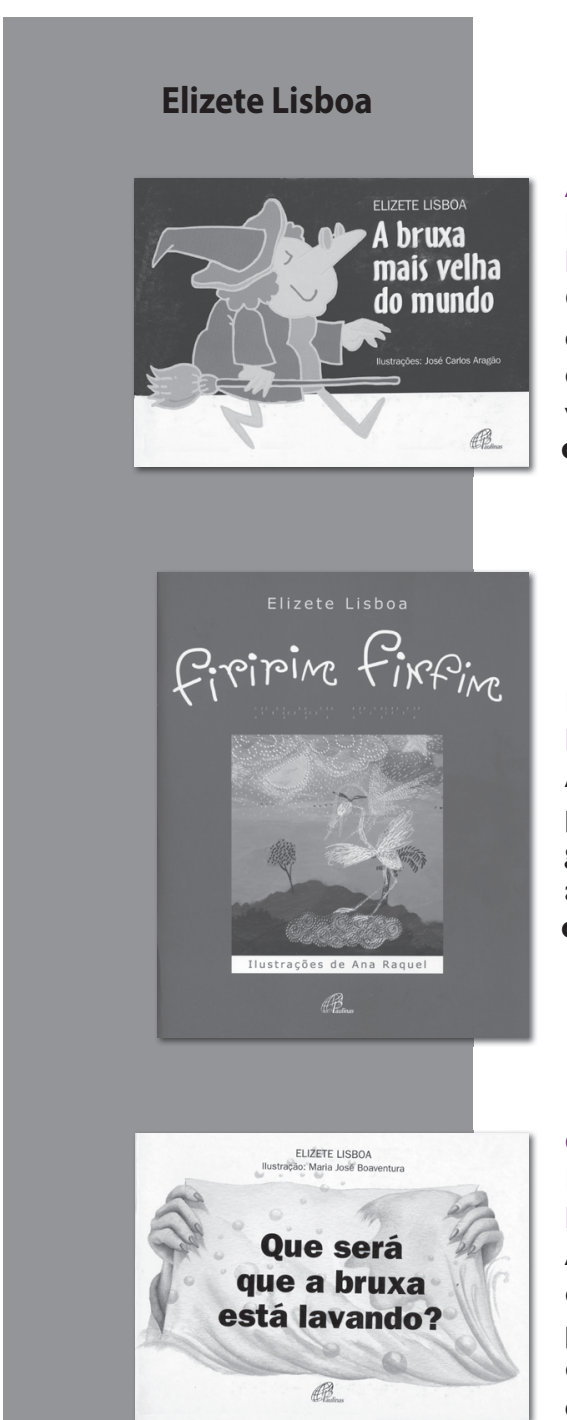

\section{FIRIRIM FINFIM}

Ilustradora: Ana Raquel

A galinha e o macaco saem pra passear e se deparam com uma garça deselegante e de cara amarrada. $O$ que estaria errado? Cód.: 512419 Págs: 32 ISBN: 9788535620719

\section{QUE SERÁ QUE A BRUXA ESTÁ LAVANDO?}

Ilustradora: Maria José Boaventura A bruxinha de Elizete adora água, espuma, canção: lava tapete, prato, pato, lava boneco de pau e boneca de pano. Lava até segredos...

Cód.: 5079|| Págs: 24 ISBN: 97885356|5920

\section{- CHAPEUZINHO VERMELHO}

Adaptação: Bia Villela

Bia nos faz novamente mergulhar na beleza e no encanto desse famoso clássico infantil como se fosse a primeira vez. Cód.: 5086|6 Págs: 24 ISBN: 97885356/66/3

\section{BENQUERER BEM AMAR}

llustradora: Maria José Boaventura Uma patinha nos ensina que a vida se realiza em diversos momentos: nos tempos de tempestades, nos tempos de brincar, de bem querer e de bem amar. Cód.: 5 I6864 Págs: 32 ISBN: 9788535625585

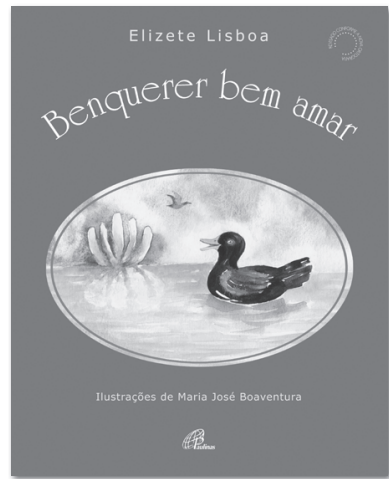

\section{Cláudia Cotes}

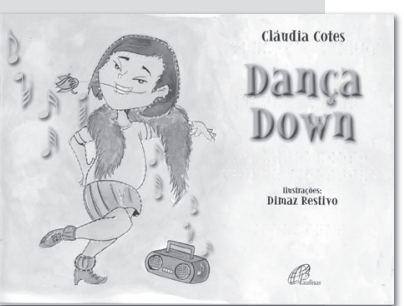

\section{DANÇA DOWN}

llustrador: Dimaz Restivo Cláudia junta Síndrome de Down e deficiência visual para criar esta obra cheia de humor e sensibilidade.

Cód.: 513504 Págs: 24 ISBN: 9788535622188

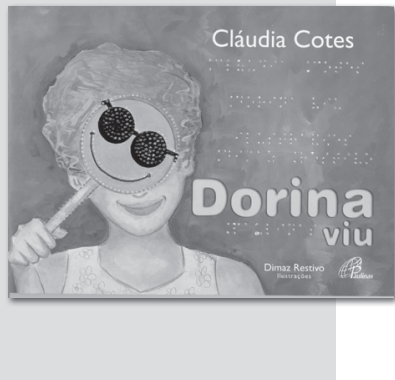

\section{DORINA VIU}

llustrador: Dimaz Restivo A história cheia de vida e determinação de Dorina Nowill em um livro gostoso de ler $\mathrm{e}$ de ver.

Cód.: 509043 Págs: 24 ISBN: 9788535617030

\section{À venda na Rede Paulinas de Livrarias Se preferir, ligue 08007010081 ou acesse www.paulinas.org.br}

